\title{
Epidemiology of Dysmenorrhea among University Students in Egypt
}

\author{
Nesreen AA Shehata ${ }^{1}$, Ahmed E Arafa ${ }^{2}$, Hamada A Abd El Wahed ${ }^{1}$, Ashraf S Fahim ${ }^{1}$ \\ and Gaber K Hussein ${ }^{1}$
}

${ }^{1}$ Department of Gynecology and Obstetrics, Beni Suef University, Egypt

${ }^{2}$ Department of Public Health, Beni Suef University, Egypt

*Corresponding author: Nesreen AA Shehata, Department of Gynecology and Obstetrics, Beni Suef University, 60 al fustat Misral kadeema, Cairo, PO Box: 11412,Egypt, Tel:00201024150605, E-mail:nesoomar@yahoo.com

\begin{abstract}
Background: Dysmenorrhea is the most common gynaecological symptom among young women. It results in negative physical and psychological consequences. The aim of this study was to investigate the epidemiology of dysmenorrhea and detect the sources of knowledge about menstrual disorders among female students in Beni-Suef University, Egypt.

Methods: A total of 1908 university female students attending all faculties $(n=28)$ of Beni-Suef University and representing all academic years were selected, using a multistage random sampling, to participate in this cross-sectional study. An Arabic-language structured questionnaire was designed and included questions about the socio-demographic characteristics of the university students, menstrual history and history of dysmenorrhea during 2017 and sources of knowledge about dysmenorrhea.

Results: Of the interviewed students, $92.9 \%$ experienced dysmenorrhea during 2017. Age, residence, educational level of parents, exposure to passive smoking, circumcision and physical activity showed no statistically significant differences between students who experienced dysmenorrhea and those who did not ( $p>0.05)$. Backaches, nervousness and irritation, and acne and flushing were the most common symptoms associated with menses, $65.7 \%, 51 \%$, and $47.3 \%$, respectively. Students referred to family members $(72.8 \%)$, friends $(24.3 \%)$, teachers or lecturers $(21.4 \%)$, TV and the Internet $(17.2 \%)$, and physicians or nurses $(6.9 \%)$ to acquire information about dysmenorrhea.

Conclusion: Dysmenorrhea is highly prevalent among university students in Beni-Suef. Further research should focus on the adaptive techniques used by the students to mitigate the negative impacts of dysmenorrhea.
\end{abstract}

\section{Keywords}

Dysmenorrhea, University students, Risk factors

\section{Introduction}

Dysmenorrhea or painful menstruation is a state of unpleasent cramping sensation of uterine origin. Although it may present alone, variant complaints usually accompany in the form of achings and spasms, gasterointestinal tract (GIT) symptoms or irritation and nervousness [1]. Dysmenorreha usually affect young women at school/university age leading to school/university absence, academic underachievement and undermined quality of life [1-3]. However, the awareness of young women about dysmenorrhea, which depends mainly on the source of knowledge, may have an impact on their ability to cope with such symptoms [4]. Physicians could play a pivotal role in controlling dysmenorrhea and its associated symptoms by providing comfort measures and helping in anxiety relief. They could also check for the physical and psychological wellbeing of the young women and offer them the required knowledge [4].

Various risk factors have been suggested to be associated with dysmenorrhea such as hormonal imbalance, failure to cope with stress, greater BMI, younger age of menarche, nutritional deficiencies, smoking or exposure to passive smoking, and lack of physical activity [5-10]. Although many international studies have investigated the epidemiology of dysmenorrhea among young women [11-14], only few national studies did [15-17]. Understanding the epidemiology of dysmenorrhea among university students in Beni-Suef may help in designing awareness programs tailored to suit the social and cultural criteria of the community

Citation: Shehata NAA, Arafa AE, EI Wahed HAA, Fahim AS, Hussein GK (2018) Epidemiology of Dysmenorrhea among University Students in Egypt. Int J Womens Health Wellness 4:073. doi.org/10.23937/2474$1353 / 1510073$

Accepted: June 09, 2018: Published: June 11, 2018

Copyright: (C) 2018 Shehata NAA, et al. This is an open-access article distributed under the terms of the Creative Commons Attribution License, which permits unrestricted use, distribution, and reproduction in any medium, provided the original author and source are credited. 
and help students get over the negative health consequences of dysmenorrhea.

In this regards, this study aims at detecting the occurence and correlates of dysmenorrhea among female students in Beni-Suef University and exploring the sources of information they use to know about menstruation and menstrual disorders.

\section{Methods}

This cross-sectional study was conducted on a total of 1908 female university students attending 28 faculties in Beni-Suef University throughout the first term of the academic year 2017/2018 between September 2017 and January 2018. The study population age ranges between 18 and 23 years in all grades of different faculties. They live in urban or rural areas of Beni Suef City. To be included in the study, female students must have had a period for the year 2017. Beni-Suef University is one of the largest educational institutions in Upper Egypt with more than 45,000 students registered in its 28 faculties; 12 faculties of humanities, social and behavioural sciences, 9 faculties of health sciences, and 7 faculties of engineering and computer sciences.

The sample size was calculated using Epi-Info version 7 Stat Calc, [Center for Disease Control (CDC), WHO], based on the following criteria; dysmenorrhea rate of $70 \%$, confidence level of $95 \%$, and margin of error of $5 \%$. A multi-stage random sampling methodology was used to include female students from all faculties and all academic years. Later, random sampling was applied from every grade level in every faculty with a minimum sample of $10 \%$ of total female students registered in each academic year.

The protocol of the study has been approved from the Research Ethics Committee of Faculty of Medicine, Beni-Suef University, and then institutional approvals were obtained. The students were informed of the purpose of the study with confirming confidentiality of data. Informed verbal consents were obtained from all students before participation.

For data collection, we prepared an Arabic-language structured questionnaire of two sections; section one included socio-demographic characteristics, whether the university student was physical active or not, marriage status, circumcision and sleep quality (assessed by the tool called the Pittsburgh Sleep Quality Index (PSQI). This version was translated and adjusted to be easy for students to answer. Quality of sleep during menstruation was assessed. PSQI consisted of ten questions, which defined seven parts: Subjective sleep quality; sleep latency; duration of sleep (sleeping hours); sleep efficiency; sleep disturbance; need for medications to sleep; and day dysfunction due to sleepiness. The maximum score is 21 points. Students scoring more than five points were classified as bad sleepers)
[18]. Also in section one, students answered questions about exposure to passive smoking, age at menarche, duration of the menstrual cycle and flow days (counting the number of days of menstruation by students has been used to assess menstrual blood loss. Based on this method, increased menstrual flow is documented if the menstrual period lasts for more than seven days/ cycle [19]. The second section questioned if the girl had experienced dysmenorrhea, its frequency and duration during the previous year of the study (2017), details of menstrual pain (onset, location, type, duration etc), any medications received for menstrual pain, other clinical manifestations associated with menses, history of infertility in married females, history suggestive of endometriosis (pelvic pain that worsens with menstruation, dyspareunia and painful bowel movements or urination) and the main sources of information about dysmenorrhea girls resorted to. Dysmenorrhea was defined as menstrual pelvic pain that required rest or interfered with regular activities rather than occasional cramping pains [20]. Dyspareunia was described as genital pain occurs during sexual intercourse [21]. Quantification of dysmenorrhea and severity grading were evaluated using visual analogue scale (VAS).

The VAS was drawn as a $10-\mathrm{cm}$ line explaining female student's opinion of the degree of pain. One side of the line represented "unbearable pain", and the other side represented "no pain at all". Students were asked to rate the degree of pain by making a mark on the line. The scores received from the scale were classified into mild dysmenorrhea if it was between 1 and 3 points moderate between 4 and 7 points, and severe between 8 and 10 points [22].

A pilot study was conducted on 200 students of the recruited sample to assess clearance of questionnaire items and their suitability for the study. Accordingly a structured questionnaire form was finalized and used for collection of data for all participants equally. It included two sections with items described above. Each participant answered the given questions in 60 minutes without interference from any interviewer. The Cronbach's alpha for the reliability of the questionnaire was 0.76 while content validity was again judged by a professor of public health and a professor of gynecology and obstetrics. A trained team of medical students with a supervisor from the Public Health Department interviewed the university students, collected and analyzed all data. Analysis of information in each questionnaire was done into 3 stages. The first stage of analysis included the process of initial coding, whereby each line of the data was considered to identify keywords; these were highlighted because they retained participants' words. The next stage of information analysis involved bringing similar categories together into broader themes. Third stage included further category development leading to final themes to be statistically analyzed [23]. 
Data were analyzed using the software, Statistical Package for Social Science (SPSS Inc. Released 2009, PASW Statistics for Windows, version 18.0: SPSS Inc., Chicago, Illinois, USA). Frequency distribution as percentage and descriptive statistics in the form of mean and standard deviation were calculated. Chi-square, t-test and correlations were done whenever needed and $p$ values of less than 0.05 were considered significant.

\section{Results}

A total of 1908 university students with a mean age of $20.8 \pm 1.7$ years participated in this study. Of them, $61.9 \%$ were living in urban areas and $38.1 \%$ were residing rural areas. The educational level of the parents of the participating students was as the following;

Table 1: Socio-demographic and gynecological characteristics of the participating university students, Beni-Suef University, 2017-2018.

\begin{tabular}{|c|c|c|}
\hline \multicolumn{2}{|c|}{$\begin{array}{l}\text { Socio-demographic and Gynaecological } \\
\text { Data }\end{array}$} & $\begin{array}{l}\text { Study Group } \\
n=1908(\%)\end{array}$ \\
\hline \multicolumn{2}{|c|}{ Age (Mean \pm Sd) } & $20.8 \pm 1.7$ \\
\hline \multirow[t]{2}{*}{ Residence } & Urban & $1181(61.9)$ \\
\hline & Rural & $727(38.1)$ \\
\hline \multirow[t]{3}{*}{ Father's Education } & Illiterate & $146(7.7)$ \\
\hline & Elementary & $321(16.8)$ \\
\hline & High & $1441(75.5)$ \\
\hline \multirow[t]{3}{*}{ Mother's Education } & Illiterate & $285(14.9)$ \\
\hline & Elementary & $322(16.9)$ \\
\hline & High & $1301(68.2)$ \\
\hline \multicolumn{2}{|l|}{ Physical Activity } & $399(20.9)$ \\
\hline \multicolumn{2}{|c|}{ Sleeping Hours/Day (Mean \pm Sd) } & $8.3 \pm 1.6$ \\
\hline \multicolumn{2}{|c|}{ Sleeping Quality score points (Mean \pm Sd) } & $3.5 \pm 2.0$ \\
\hline \multicolumn{2}{|c|}{ Exposure to Passive Smoking } & $790(41.4)$ \\
\hline \multicolumn{2}{|c|}{ Circumcision } & $957(50.2)$ \\
\hline \multicolumn{2}{|l|}{ Marriage } & $87(4.6)$ \\
\hline \multicolumn{2}{|c|}{ Menarche Age (Mean \pm Sd) } & $13.0 \pm 1.4$ \\
\hline \multicolumn{2}{|c|}{ Menstrual Cycle Duration (Mean \pm Sd) } & $28.4 \pm 5.9$ \\
\hline \multicolumn{2}{|c|}{ Menstrual Flow Duration (Mean \pm Sd) } & $5.2 \pm 1.4$ \\
\hline
\end{tabular}

\section{Dysmenorrhea}

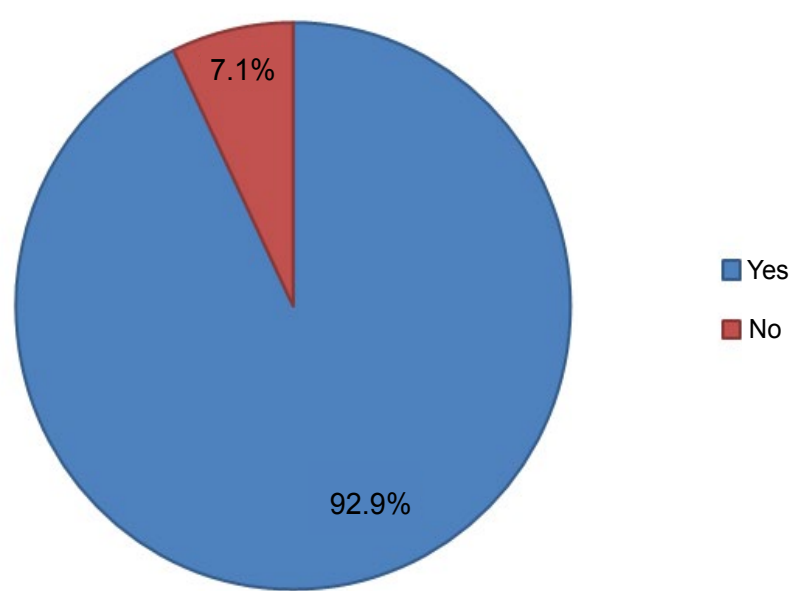

Figure 1: Occurrence of dysmenorrhea during the previous year as reported by the participating university students, Beni-Suef University, 2017-2018.
7.7\% and $20.9 \%$ illiterate fathers and mothers, $16.8 \%$ and $16.9 \%$ completed their elementary education and $75.5 \%$ of fathers and $68.2 \%$ of mothers had a higher degree. Less than $20 \%$ of girls reported regular exercise activity, $4.6 \%$ were married, $41.4 \%$ stated exposure to passive smoking, and $50.2 \%$ were circumcised. The mean hours of sleeping per day were $8.3 \pm 1.6$ hours/ day while mean sleep quality score was $3.5 \pm 2.0$ points. The participants' age of menarche was $13 \pm 1.4$ years, and the menstrual cycle duration was $28.4 \pm 5.9$ days, with $5.2 \pm 1.4$ flow days (Table 1 ).

Of the 1908 interviewed students, 1773 (92.9\%) experienced dysmenorrhea during 2017 (Figure 1). Neither the socio-demographic factors such as residence and parents' education, nor the gynaecological factors such as age of menarche, circumcision, menstrual cycle duration, and flow days were associated with having dysmenorrhea during 2017 ( $p>0.05$ ). Also, exposure to passive smoking and physical inactivity were not related to dysmenorrhea ( $p>0.05$ ). However, sleep quality score was related to dysmenorrhea $(p<0.0001)$ (Table 2). Backaches, nervousness and irritation, and acne and flushing were the most common symptoms associating with menses, $65.7 \%, 51 \%$, and $47.3 \%$, respectively (Table 3 ). The main sources of information about menses and dysmenorrhea were mainly family members $(72.8 \%)$, friends (24.3\%), teachers/lecturers (21.4\%), and TV/Internet (17.2\%), while only $6.9 \%$ of the students resorted to physicians/nurses (Table 4).

Among those who reported menstrual pain or dysmenorrhea (92.9\%), detailed results of pain namely frequency, onset, duration, type and site presented as follows: Frequency of dysmenorrhea: Majority of students $(90.2 \%)$ experienced dysmenorrhea each month. Onset of pain: Most of students (73.3\%) have reported onset of pain on first day, $18.7 \%$ reported pain to start before menstruation, $7.6 \%$ declared to have pain started on day 2 or 3 and only $0.3 \%$ of participants reported end of pain after stoppage of menstrual flow. So, it was shown in results that most of participants reported dysmenorrhea on day 1 of menses. Duration of menstrual pain as reported by students: Sixty seven percent declared to have menstrual pain for 2 days, 17.3\% reported 2 days of pain, and $13.7 \%$ reported pain for 4 days while only $1.9 \%$ had pain for 1 day after stoppage of menses. Menstrual pain site was reported to be lower abdominal pain in two thirds of students (62\%), in addition to lower backache in (18\%) and radiation of supra pubic pain to thighs in (4.5\%). Moreover, $15.5 \%$ suffered from generalized body aches. Type of pain was reported as spasmodic by most of students (76.9\%) but $13.2 \%$ described piercing type of pain. Shooting pain was declared by $3.5 \%$ while stabbing type was reported by $6.3 \%$ of girls.

Dysmenorrhea was prevalent in 1773 (92.9\%) of study population. VAS scale was used for quantification of dysmenorrhea. Twenty eight percent of students re- 
Table 2: Factors associated with occurrence of dysmenorrhea during the previous year among the participating university students, Beni-Suef University, 2017-2018.

\begin{tabular}{|c|c|c|c|c|}
\hline \multicolumn{2}{|c|}{ Socio-demographic and Gynaecological Data } & $\begin{array}{l}\text { Dysmenorrhea } \\
n=1773(\%)\end{array}$ & $\begin{array}{l}\text { No Dysmenorrhea } \\
n=135(\%)\end{array}$ & $P$ value \\
\hline \multicolumn{2}{|l|}{ Age (Mean \pm Sd) } & $20.8 \pm 1.7$ & $20.6 \pm 1.9$ & 0.365 \\
\hline \multirow[t]{2}{*}{ Residence } & Urban & $1103(62.2)$ & $78(57.8)$ & \multirow[t]{2}{*}{0.176} \\
\hline & Rural & $670(37.8)$ & $57(42.2)$ & \\
\hline \multirow[t]{3}{*}{ Father's Education } & Illiterate & $133(7.5)$ & $13(9.6)$ & \multirow[t]{3}{*}{0.443} \\
\hline & Elementary & $295(16.6)$ & $26(19.3)$ & \\
\hline & High & $1345(75.9)$ & $96(71.1)$ & \\
\hline \multirow[t]{3}{*}{ Mother's Education } & Illiterate & $261(14.7)$ & $24(17.8)$ & \multirow[t]{3}{*}{0.562} \\
\hline & Elementary & $298(16.8)$ & $24(17.8)$ & \\
\hline & High & $1214(68.5)$ & $87(64.4)$ & \\
\hline \multicolumn{2}{|l|}{ Physical Activity } & $373(21.0)$ & $26(19.3)$ & 0.358 \\
\hline \multicolumn{2}{|c|}{ Sleeping Hours/Day (Mean \pm Sd) } & $8.3 \pm 1.6$ & $8.3 \pm 1.5$ & 0.986 \\
\hline \multicolumn{2}{|c|}{ Sleeping Quality score points (Mean \pm Sd) } & $3.5 \pm 2.0$ & $2.5 \pm 1.8$ & $P<0.0001^{*}$ \\
\hline \multicolumn{2}{|c|}{ Exposure to Passive Smoking } & $739(41.7)$ & $51(37.8)$ & 0.213 \\
\hline \multicolumn{2}{|c|}{ Circumcision } & $883(49.8)$ & $74(54.8)$ & 0.151 \\
\hline \multicolumn{2}{|l|}{ Marriage } & $80(4.5)$ & $7(5.2)$ & 0.420 \\
\hline \multicolumn{2}{|c|}{ Menarche Age (Mean \pm Sd) } & $13.0 \pm 1.4$ & $13.1 \pm 1.6$ & 0.667 \\
\hline \multicolumn{2}{|c|}{ Menstrual Cycle Duration (Mean \pm Sd) } & $28.4 \pm 5.8$ & $28.1 \pm 6.6$ & 0.669 \\
\hline \multicolumn{2}{|c|}{ Menstrual Flow Duration (Mean \pm Sd) } & $5.2 \pm 1.4$ & $5.3 \pm 1.7$ & 0.604 \\
\hline
\end{tabular}

*Highly significant.

Table 3: Other clinical manifestations associated with menses as reported by the participating university students, Beni-Suef University, 2017-2018.

\begin{tabular}{|l|l|}
\hline Clinical Manifestations & $\begin{array}{l}\text { Study Group } \\
\mathbf{n}=1908(\%)\end{array}$ \\
\hline Backaches & $1253(65.7)$ \\
\hline Nervousness/Irritation & $973(51.0)$ \\
\hline Acne/Flushing & $903(47.3)$ \\
\hline General Aching & $792(41.5)$ \\
\hline Headache & $455(23.8)$ \\
\hline Breast Tenderness & $439(23.0)$ \\
\hline Anorexia/Vomiting & $357(18.7)$ \\
\hline Abdominal Distension & $344(18.0)$ \\
\hline Insomnia & $195(10.2)$ \\
\hline Dysuria & $192(10.1)$ \\
\hline Others & $148(7.8)$ \\
\hline
\end{tabular}

ported severe pain (8-10). Forty nine percent reported moderate score of pain (4-7) and the rest of (23\%) students had mild pain. Twenty percent of students who experienced dysmenorrhea reported receiving pain killers for menstrual pain. The rest of participants reported taking rest and hot drinks that helped in relieving pain.

Eighty seven (4.6\%) students were married; none of them gave history of infertility. Only $5.7 \%$ reported history of infertility. Among those who reported dysmenorrhea (1773), $0.7 \%$ reported worsening of pain with menstruation. None of married students had dyspareunia. None of participants reported painful bowel movements or urination.

\section{Discussion}

Dysmenorrhea is a public health concern as it carries negative impacts on physical and emotional health, school attendance, and academic achievement $[1,3]$. In this cross-sectional study, the occurrence of
Table 4: Main sources of information about dysmenorrhea and menses as reported by the participating university students, Beni-Suef University, 2017-2018.

\begin{tabular}{|l|l|}
\hline Sources of Information & $\begin{array}{l}\text { Study Group } \\
\mathbf{n = 1 9 0 8}(\mathbf{\%})\end{array}$ \\
\hline Family & $1389(72.8)$ \\
\hline Friends & $463(24.3)$ \\
\hline Teachers/Lecturers & $408(21.4)$ \\
\hline TV/Internet & $329(17.2)$ \\
\hline Physicians/Nurses & $131(6.9)$ \\
\hline
\end{tabular}

dysmenorrhea and its associations during 2017 amongst female students in Beni-Suef University were evaluated. A total of 1908 university students representing 92.9\% of the participants reported dysmenorrhea. In a study conducted over 664 girls attending secondary and nursing schools in Mansoura (north of Egypt), the results put the prevalence of dysmenorrhea at $75 \%$ [15]. Another study on 845 girls attending four secondary schools in Assiut (upper Egypt) reported a prevalence of $76.1 \%$ [16]. However, both studies detected the rates of dysmenorrhea during only three months prior to the study. On the other hand, a study on girls attending two nursing schools in Minia (upper Egypt) showed a high prevalence of dysmenorrhea reaching $94.4 \%$ of the participants, however this study included only 160 students and did not clarify the length of dysmenorrhea recall [17]. Worldwide, the prevalence of dysmenorrhea varied widely according to the age of the study group, the length of recall/follow-up, and definition of pain whether any pain or pain interrupting with daily activities. In Japan, a prevalence of only $15 \%$ was detected in a one-month prospective study over 823 women (18-51 years) [24], while in a study on Chinese women (20-34 years), the 12 months follow-up 
resulted in a prevalence of $44.4 \%$ [8]. The rates reached $60 \%$ among Canadian women [11], 61\% in Saudi Arabia [14], 76\% in the USA [25], and 85.1\% in Ethiopia [12].

In the current study, age played no role in the occurrence of dysmenorrhea which contradicted many previous studies $[13,16,26]$. However, it should be taken into consideration that the age of the university students ranged from 18 to 23 years, and this tight range might explain why the impact of age was not detected in the current study. Other reports concluded that dysmenorrhea peaks in late adolescence, then the incidence falls with increasing age $[11,24,25,27]$.

Also, early menarche was not associated with occurrence of dysmenorrhea which consisted with previous studies $[11,28]$, but did not agree with others $[15,16]$. It is suggested that older women and those with earlier menarche (more gynaecological years) have been exposed for longer period to uterine prostaglandins making them more prone to experience dysmenorrhea [29]. In our study, students with dysmenorrhea suffered poor quality of sleep. In agreement with our result, it was found that dysmenorrheic women had more disturbed sleep and subjective sleepiness than controls. Their sleep efficiency was reduced when experiencing menstrual pain, with increased wakefulness, movement [30].

Besides, exposure to passive smoking and physical inactivity were not associated with dysmenorrhea which consisted with previous reports $[25,28]$. It is thought that Nicotine might minimize the endometrial blood flow in addition to its disturbing effect on the hormonal levels $[9,10]$, while physical activity could enhance the blood flow to the uterus and decrease the water retention [31]. Our results also showed that menstrual cycle duration and flow days showed no difference between students who experienced dysmenorrhea and those who did not, a finding that contradicted that of Shiferaw, et al. [12], El-Gilany, et al. [15], Mohamed [16], and Weismann, et al. [25] who concluded that women with longer menstrual cycles were more likely to have dysmenorrhea.

Our students stated that backaches, nervousness and irritation, and acne and flushing were the most common symptoms associated with menses, $65.7 \%, 51 \%$, and $47.3 \%$, respectively. A previous study on Egyptian women showed also that backaches and nervousness were common symptoms during menses [32].

VAS scale was used for quantification of dysmenorrhea. Pain was divided into mild, moderate and severe pain in this 3 point scale. In our study (28\%) of students reported severe pain (8-10). Forty nine percent reported moderate score of pain (4-7) and the rest of (23\%) students had mild pain. In contrast to other study where it was revealed that $53.93 \%, 21.34 \%$ and $24.42 \%$ of students had mild, moderate and severe pain (dysmenor- rhea) respectively [22]. Twenty percent of students who experienced dysmenorrhea reported receiving pain killers for menstrual pain. However, in a study including 408 students, the need for medication was reported in $225 / 408$ (55.2\%) subjects [20].

Family members and friends were the main sources of information regarding dysmenorrhea; $72.8 \%$ and $24.3 \%$, respectively which come in accordance with previous reports [17,32-34]. Only $4.9 \%$ of girls in our study sought information related to dysmenorrhea from physicians or nurses. This could be attributed to the sensitivity of menstrual issues and fear of young women to share private data. Meanwhile, students feel reluctant to seek medical advice and prefer their family members and close friends instead. Further, it seems that there are no available programs or awareness sessions about menstrual disorders offered by Beni-Suef University.

In conclusion, occurrence of dysmenorrhea among university students in Beni-Suef was very high. Family and friends were the main sources of knowledge. Further research should focus on investigating the coping strategies of the students to manage their dysmenorrhea and designing educational programs that allow physicians and/or nurses to discuss the menstrual problems with the university students or young females.

Implications for Practice and/or Policy include encouraging awareness of medical health problems through improving sources of knowledge. This will give systematized methods of treatment involving well informed patients in the treatment plan. Policy development can be through extended process of communication and interaction.

One of the limitations of our study that population of high education level was chosen. Results of main sources of information about dysmenorrhea might have been biased. However, from other studies in a systematic review of prevalence of dysmenorrhea, it was found no association with woman's education or education years [35]. In addition, as described above, health programs or awareness sessions about menstrual disorders are still not offered by Beni-Suef University. Moreover, our results revealed that students preferred to ask a family member or a friend more than seeking a health giver advice.

\section{Acknowledgement}

We thank all our participants.

All authors contributed in design of the study, collection of data, interpreting results and writing discussion in addition to revising work.

\section{References}

1. French L (2005) Dysmenorrhea. Am Fam Physician 71: 285-291.

2. Ballagh SA, Heyl A (2008) Communicating with women about menstrual cycle symptoms. J Reprod Med 53: 837846. 
3. Kadir RA, Edlund M, Von Mackensen S (2010) The impact of menstrual disorders on quality of life in women with inherited bleeding disorders. Haemophilia 16: 832-839.

4. Dasgupta A, Sarkar M (2008) Menstrual hygiene: How hygienic is the adolescent girl? Indian J Community Med 33 77-80.

5. Cerin A, Collins A, Landgren BM, Eneroth P (1993) Hormonal and biochemical profiles of premenstrual syndrome. Treatment with essential fatty acids. Acta Obstet Gynecol Scand 72: 337-343.

6. Dawood MY (2006) Advances in primary dysmenorrhea. Obstet Gynecol 108: 428-441.

7. Alvir JM, Thys-Jacobs S (1991) Premenstrual and menstrual symptom clusters and response to calcium treatment. Psychopharmacol Bull 27: 145-148.

8. Wang L, Wang X, Wang W, Chen C, Ronnennberg A, et al. (2004) Stress and dysmenorrhoea: A population based prospective study. Occup Environ Med 61: 1021-1026.

9. Parazzini F, Tozzi L, Mezzopane R, Luchini L, Marchini M, et al. (1994) Cigarette smoking, alcohol consumption, and risk of primary dysmenorrhea. Epidemiology 5: 469-472.

10. Baron JA, La Vecchia C, Levi F (1990) The antiestrogenic effect of cigarette smoking in women. Am J Obstet Gynecol 162: $502-514$

11. Burnett MA, Antao V, Black A, Feldman K, Lea R, et al. (2005) Prevalence of primary dysmenorrhea in Canada. J Obstet Gynaecol Can 27: 765-770.

12. Shiferaw MT, Wubshet M, Tegabu D (2014) Menstrual problems and associated factors among students of Bahir Dar University, Amhara National Regional State, Ethiopia: A cross-sectional survey. Pan Afr Med J 17: 246.

13. Andersch B, Milsom I (1982) An epidemiologic study of young women with dysmenorrhea. Am J Obstet Gynecol 144: 655-660.

14. Ibrahim NK, AIGhamdi MS, Al-Shaibani AN, AIAmri FA, Alharbi HA, et al. (2015) Dysmenorrhea among female medical students in King Abdulaziz University: Prevalence, predictors and outcome. Pak J Med Sci 31: 1312-1317.

15. El-Gilany A-H, Badawi K, El-Fedawy S (2005) Epidemiology of dysmenorrhea among adolescent students in Mansoura, Egypt. East Meditterr Health J 11: 155-163.

16. Mohamed EM (2012) Epidemiology of dysmenorrhea among adolescent students in Assiut City, Egypt. Life Sci J 9: 348-353.

17. Abd El-Hameed NA, Mohamed MS, Ahmed NH, Ahmed ER (2011) Assessment of dysmenorrhea and menstrual hygiene practices among adolescent girls in some nursing schools at EL-Minia Governorate, Egypt. Life Sci J 7: 1-10.

18. Bertolazi AN, Fagondes SC, Hoof L, Dartora EG, Miozzo ICS, et al. (2011) Validation of the Brazilian Portuguese version of the Pittsburgh sleep quality index. Sleep Med 12: 70-75.

19. Chimbira TH, Anderson ABM, Turnbull AC (1980) Relation between measured menstrual blood loss and patient's subjective assessment of loss, duration of bleeding, number of sanitary towels used, uterine weight and endometrial surface area. Br J Obstet Gynaecol 87: 603-609.

20. Giovanni G, Serena F, Anjeza X, Marianna C, Federica P, et al. (2012) Prevalence of menstrual pain in young women: What is dysmenorrhea? J Pain Res 5: 169-174.

21. Heim LJ (2001) Evaluation and differential diagnosis of dyspareunia. Am Fam Physician 63: 1535-1544.

22. Shah S, Makwana K, Shah P (2015) Menstrual characteristics and prevalence of dysmenorrhoea among female physiotherapy students. International Journal of Medicine \& Health Research 1: 1-8.

23. Noble H, Smith J (2014) Qualitative data analysis: A practical example. Evid Based Nurs 17: 2-3.

24. Ohde S, Tokuda Y, Takahashi O, Yanai H, Hinohara S, et al. (2008) Dysmenorrhea among Japanese women. Int J Gynaecol Obstet 100: 13-17.

25. Weissman AM, Hartz AJ, Hansen MD, Johnson SR (2004) The natural history of primary dysmenorrhoea: A longitudinal study. BJOG 111: 345-352.

26. Makhlouf EMM, AbdullHameed SM (2010) Impact of psychological aspects of primary dysmenorrhea among employee female in university city, Assuit Governorate. AAMJ 8: 61-78.

27. Eryilmaz G, Ozdemir F, Pasinlioglu T (2010) Dysmenorrhea prevalence among adolescents in eastern Turkey: Its effects on school performance and relationships with family and friends. J Pediatr Adolesc Gynecol 23: 267-272.

28. Arafa AE, Khamis Y, Hassan HE, Saber NM, Abbas AM (2018) Epidemiology of dysmenorrhea among workers in Upper Egypt; A cross sectional study. Middle East Fertility Society Journal 23: 44-47.

29. Shrotriya C, Ray A, Ray S, Thomas GA (2012) Menstrual characteristics and prevalence and effect of dysmenorrhea on quality of life in medical students. Int J Collab Res Intern Med Public Health 4: 276-294.

30. lacovides S, Avidon I, Baker FC (2015) What we know about primary dysmenorrhea today: A critical review. Hum Reprod Update 21: 762-778.

31. Johnson WG, Carr-Nangle RE, Bergeron KC (1995) Macronutrient intake, eating habits, and exercise as moderators of menstrual distress in healthy women. Psychosom Med 57: 324-330.

32. Arafa AE, Sensosy SA, Helmy HK, Mohamed AA (2018) Prevalence and patterns of dysmenorrhea and premenstrual syndrome among Egyptian girls (12-25 years). Middle East Fertility Society Journal.

33. Ersog B, Balkan C, Gunay T, Onag A, Egemen A (2004) Effects of different socioeconomic conditions on menarche in Turkish female students. Early Hum Dev 76: 115-125.

34. Tiwari H, Oza UN, Tiwari R (2006) Knowledge, attitudes and beliefs about menarche of adolescent girls in Anand district, Gujarat. East Mediterr Health J 12: 428-433.

35. Ju H, Jones M, Mishra G (2014) The prevalence and risk factors of dysmenorrhea. Epidemiol Rev 36: 104-113. 